\title{
NEW PROOF OF THE GENERALIZED CHINESE REMAINDER THEOREM
}

\author{
AVIEZRI S. FRAENKEL
}

Theorem. A necessary and sufficient condition that the system of congruences $x \equiv r_{i}\left(\bmod m_{i}\right), i=1,2, \cdots, s$ be solvable is that $r_{i}-r_{j} \equiv 0$ $\left(\bmod \left(m_{i}, m_{j}\right)\right), 1 \leqq i<j \leqq s$. Any two solutions are congruent $\bmod \left[m_{1}, m_{2}, \cdots, m_{s}\right]$.

Proof. ${ }^{1}$ The necessity is clear. For proving the sufficiency, let $M_{0}=1, M_{i}=\left[m_{1}, m_{2}, \cdots, m_{i}\right], i \geqq 1$. Every integer $N$ in the range $0 \leqq N<M_{8}$ is uniquely representable in the form $N=a_{1} M_{0}+a_{2} M_{1}$ $+\cdots+a_{8} M_{s-1}, 0 \leqq a_{i}<M_{i} / M_{i-1}$.

The congruence $a_{1} M_{0} \equiv r_{1}\left(\bmod m_{1}\right)$ has a solution $a_{1}$ with $0 \leqq a_{1}$ $<m_{1}$. Assume that $a_{i}$ has already been found as a solution of $a_{1} M_{0}$ $+a_{2} M_{1}+\cdots+a_{i} M_{i-1} \equiv r_{i}\left(\bmod m_{i}\right)$, for all $i<n$. The congruence $a_{1} M_{0}+a_{2} M_{1} \cdots+a_{n} M_{n-1} \equiv r_{n}\left(\bmod m_{n}\right)$ is solvable for $a_{n}$ if and only if $^{2} \quad c_{n}-r_{n} \equiv 0 \quad\left(\bmod \left(M_{n-1}, m_{n}\right)\right)$, where $c_{n}=a_{1} M_{0}+a_{2} M_{1}+\cdots$ $+a_{n-1} M_{n-2}$. Now $c_{n} \equiv r_{i}\left(\bmod m_{i}\right)$, and hence

$$
c_{n}-r_{n} \equiv 0\left(\bmod \left(m_{i}, m_{n}\right)\right), \quad i=1,2, \cdots, n-1,
$$

by the hypothesis. Thus

$$
c_{n}-r_{n} \equiv 0\left(\bmod \left[\left(m_{1}, m_{n}\right),\left(m_{2}, m_{n}\right), \cdots,\left(m_{n-1}, m_{n}\right)\right]\right) .
$$

Since $^{3}\left[\left(m_{1}, m_{n}\right),\left(m_{2}, m_{n}\right), \cdots,\left(m_{n-1}, m_{n}\right)\right]=\left(M_{n-1}, m_{n}\right)$, an integer $a_{n}$ with $0 \leqq a_{n}<M_{n} / M_{n-1}$ is uniquely determined, and thus $N$ is determined. ${ }^{4}$ If $N_{1}$ is any integer satisfying $N_{1} \equiv r_{i}\left(\bmod m_{i}\right)$, $i=1,2, \cdots, s$, then $N_{1} \equiv N\left(\bmod M_{s}\right)$, and the proof is complete.

Note. The necessity part was already established by the priest Yih-hing in the eighth century. Stieltjes proved both the necessity and sufficiency of the condition. For these and related references, see [2, pp. 57-64]. An existence proof is given in [4, Theorem 3-12, p. 34]. The solution which is produced in the conventional proof of the Chinese Remainder Theorem (i.e., the case $\left(m_{i}, m_{j}\right)=1$ for $i \neq j$ ), is only an equivalence class; it is not known a priori in which interval of two consecutive multiples of $M_{s}$ the solution will be found. The

Received by the editors June 16, 1962.

${ }_{1}$ References are given in the footnotes for the sake of the nonspecialist reader.

2 See e.g. [4, Theorem 3-10, p. 32].

3 See e.g. [4, problem 2, p. 23].

4 The upper bound for $a_{n}$ follows from the identity

$$
m_{n} /\left(M_{n-1}, m_{n}\right)=\left[M_{n-1}, m_{n}\right] / M_{n-1}=M_{n} / M_{n-1} \text {. }
$$


feature of the present proof is that a solution $N$ is produced which is always in the range $0 \leqq N<M_{\text {s. }}$ This is important in some applications, for example, in modular computation [4], which is a Chinese Remainder problem. Another application concerning the sieve problem $[1 ; 3]$ seems possible.

\section{REFERENCES}

1. D. G. Cantor, G. Estrin, A. S. Fraenkel and R. Turn, $A$ very high-speed digital number sieve, Math. Comp. 16 (1962), 141-154.

2. L. E. Dickson, History of the theory of numbers, Vol. 2, Chelsea, New York, 1952, pp. 57-64.

3. D. H. Lehmer, The sieve problem for all-purpose computers, Math. Comp. 7 (1953), 6-14.

4. W. J. LeVeque, Topics in number theory, Vol. 1, Addison-Wesley, Reading, Mass., 1956.

5. H. B. Mann, On modular computation, Math. Comp. 15 (1961), 190-192.

UNIVERSITY OF OREGON AND

Weizmann Institute of Science, Rehovot, IsRael 